\title{
The role of NGOs in urban management: A case study of Mashhad Gonbad Sabz monuments
}

\author{
Mohammad Mehdi Keykhay Moghaddam ${ }^{*}$, Ali Ghasemi Marghashi \\ ${ }^{1,2}$ MA Student, Department of Art and Architecture, Mashhad Branch, Islamic Azad University, \\ Mashhad, Iran
}

\begin{abstract}
Keywords:

Voluntary Associations, Mashhad Gonbad Sabz

Monuments, Tomb Architecture, NGO

Correspondence:

m.moghadam628@yahoo.com

Among several subsidiaries within a large architectural design, tomb architecture has a great value for all communities. Regarding the value and importance of historical buildings, it is necessary to examine the ways of dealing with maintaining such kind of buildings. The present study aims to assess the maintenance ways of Mashhad Gonbad Sabz monuments through participating in voluntary associations due to its role in the city's architectural and historical identity. It is argued that fundamental changes seem especially necessary in voluntary associations which are used for more efficient protection of monuments. Due to structural weakness of current management and culture, the implementation of this type of associations is essential.
\end{abstract}

(C)AIMI Journals

\section{Introduction}

Shrines were erected in honor of local holy men and women showed the dominance of religious architecture in the Safavid period. These types of monuments especially those famous tombs which were located in Ardebil, Mashhad, and Iraq were considered as pilgrimage centers during Safavid period (Cambridge University, 2001). After mosques, there is no doubt that the public buildings such as tombs are common in Islamic architecture of Iran. Tomb architecture was common form of architecture rather than mosques throughout the Safavid period due to people's respect and honor towards holy saints (Azhand, 2000). In the process of construction of tomb complexes in Iranian architecture, the structure of tombs gradually changed from square into the octagonal domed structure. This octagonal domed 
structure provided enough open space for performing Tawaf (circumambulation) and pilgrimage. In the central part of this octagonal structure usually monuments are placed (Falamaki, 2009b).

The most prominent samples of the Safavid architecture made of sun dried mud brick and are detailed in terms of their architectural decorations and ornaments. Cross-shaped minai tiles are used for decorating interior and their normal surfaces. Furthermore, there are deep indentations fashioned into all four garden walls. (Hillenbrand, 2004). The majority of ceremonies and related events are conducted inside of these octagonal domed structures. The constructions of hospices (Khanqahs) are located on the eastern fringe of octagonal domed structure.

\section{The Literature Review}

Gonbad Sabz monument is the tomb of Sheikh Mohammad Momen Aref Astrabadi Who died at $904 \mathrm{AD}$. He often was spending his more time chanting and praying, so when he died, he was buried, according to his will, by his disciples in this tomb. Now, this tomb which belongs to the Safavid period is situated on the Akhund Khorasani Street in Mashhad. Historical documents and travelogues certify that this building had been located in the center of a large garden before the construction and reconstruction of new streets and squares on its west side. Mir Homa large cemetery was on its eastern side and Seyyed Asmaylshah Tekye's tomb who is known as Agha Shaah Tekyeha is close to it. His tomb was considered as a residence for large number of Sufis; in other words, it was a kind of Safavid hospice in which the ceremonies and related events are held. This tomb is one of the ancient relics of Mashhad and its dome covers with turquoise colored tiles comparing with other Mashhad's domes which are bricky and golden. In tomb structure, the architect paid special attention to the porch and dome and cover the walls with seven color tile mosaics. The written date on them dates back to second period of Azeri style. This historical building is conserved and protected by the Khorasan Razavi Cultural Heritage organization. Gonbad Sabz has a quadrilateral structure from inside and its exterior part is visible in the form of octagonal. Its double shell dome covered with turquoise colored tiles. Geometric proportions and drawings and building plans and facades are characteristics of architectural style of Isfahan (Pirnia, 2008). Therefore, it is essential to preserve and protect these cultural properties for present and future civilizations and generations (Hojjat, 1995). In the field of historic preservation, some actions were taken to restore this historic building. The first period of repair which was related to the inscription dates back to the spring of 1994. The second period of repair was through the summer of 1996 in which the floors and pavements were under the repair. In 2002, the third period of repair was started in which the damaged parts of dome were repaired. Tasks such as tiles repairing and cleaning were done in the fourth period of repair in 2004. In the fifth period, restoration of mural decorations and paintings on the eastern side of monument was done. In the sixth and seventh period of repair, restoration of tiles on the northwest side of building and mural decorations and paintings in the south and southwest side of building were done respectively. During the eighth period of repair throughout 2008, the architects attempted to strengthen the building. 


\section{Building Pathology}

Building damages can be divided into two general categories including natural and internal factors damages. Natural damages consist of plants growth, natural biomass, moisture, and earthquake. Internal factors damages include materials and mortar used in construction, the location of construction, and techniques, technologies, and methods of construction. The strength of building against internal and external factors and building probable problems should be taken into account simultaneously before starting the construction (Falamaki, 2005). There are some

effective proposals for conservation and restoration of monuments such as creating channels to control and remove the moisture of building, strengthening the existing foundation, setting traffic restrictions, setting environmental conditions, and attracting the public authorities and the people's attention to the cultural and historical values of public buildings and heritages. Education and awareness are essential factors in order to encourage people and attract their support. These measures and partnerships should be done through training at schools, out of schools, and universities through books, television, radio, cinema, mobile, and exhibitions (Falamaki, 1995).

\section{Non- Governmental Organizations (NGOs)}

Non-governmental organizations (NGOs), in the most general sense, refer to the organizations which are not directly part of the structure of government, but play very important role as intermediaries between individuals (community atoms) and the ruling authorities and the society itself.

These are organizations with independent legal personality, non-governmental, nonpolitical, non-profit which do voluntary activities with cultural, social, religious, and humanitarian trends based on the rule of law and codified constitution, obey the state laws in accordance with the provisions of theirs bylaws. The budget of these organizations has been provided through donations, government organizations, and funds by the combination of these methods.

Although voluntary associations of citizens have existed throughout history, NGOs along the lines seen today especially at the international level, have been developed within the last two centuries. One of the first organizations is the International Red Cross which was founded in 1863. Report prepared by the United Nations in global governance in 1995 showed that at that time there were nearly 29,000 international non-governmental organizations. The international council on monuments and sites (ICOMOS) is the organization for the maintenance and protection of cultural heritage sites around the world. As a consequence of the Charter of Venice in 1964, ICOMOS was founded in 1965 in Warsaw to be consultant to UNESCO World Heritage. The idea behind ICOMOS comes back to the Athens conference on the restoration of historic monuments and buildings in 1931 which was set up by the International Museums Office (IMO). Some resolutions were adopted at the Second International Congress of Architects and Specialists of Historic Buildings in Venice in 1964. The first developed resolution on the protection and restoration of monuments and sites was better known as the Charter of Venice. The second resolution that was put forward by UNESCO established ICOMOS to implement the Charter. Except in 
a few cases, each member must be technically qualified expert in the maintenance field in different areas of study such as landscape architecture, architecture, archeology, urban planning, and engineering in charge of cultural heritage, art historian, and archivist (Falamaki, 2009a). Its international headquarters are located in Paris. According to the definition of NGOs, their objectives includes citizens' ability to solve their problems especially disadvantaged groups, organizing and institutionalizing citizens' participation, providing advice to government agencies, paying much attention to the environment and monuments, awareness raising among citizens through implementation of cultural programs such as poetry, music, theater, and encouraging the rich to help the charities (Imani Jajarmi, Bigdeli, \& Hanachi, 2002).

The Iranian National Committee is cultural, scientific, and technical institution. This complex was set on in 2002 and simultaneously with the International Day of ICOMOS formally began its work. Experts from cultural heritage organizations are affiliated with this institution. NGOs which continue their activities require features such as spontaneous and natural needs, common objectives, legality, documented programs and activities, partnership and participation (membership), and independence.

Mosques, other religious buildings, religious groups, and coffeehouses are known as Iranian traditional non-governmental organizations. Loan funds, charities, Islamic associations and unions, trade unions and guild, engineering systems, and other new forms of civil society which of course should gradually become free of parastatal managers.

\section{Important Measures of NGOs}

Important measures of NGOs consist of executive measures, culture, public training, research, and communicating with government departments. Executive measures refers to the official and unofficial recruitment, planning, monitoring, evaluating the productivity of natural resources and the environment, supporting the poor and certain patients, income belongs to the charity, exhibition, research, joint projects, government, public, and international donations, information of the newsletters, posters, announcements, and internet. Culture refers to the religious meetings, theater, music, painting, film advertisements, individual and collective identity, giving responsibility to the people, and protecting the monuments and cultural heritage. Public training includes training conferences, workshops, and training seminars, training experts, public and scientific lectures, and advice. Research includes a social needs assessment, improving efficiency, and sample introduction. Communicating with government departments including giving advice and holding joint meetings, joint projects, expression of bugs and suggestions to improve matters, and monitoring and controlling of public projects.

There are many different types of NGOs because they vary in their methods; therefore, they can be classified base on their scope of operations for example NGO such as Oxfam which acts in the field of poverty alleviation, facilities and provides the needed equipments and skills to enable the poor or needy people to find food and safe drinking water. In the field of international human rights organizations, Amnesty has the longest history. Amnesty International (AI) as a global movement has formed a global association of human rights defenders with more than 5.1 million members, supporters, and subscribers in over 150 
countries and regions of the world. International Freedom of Expression Exchange which was founded in 1992 is one of global networks of editors, journalists, and media executives with more than 60 NGOs that promotes and defends the right of freedom of expression.

\section{Results}

Experience shows that public institutions are reflectors of damages and social problems to the government. With a serious approach to the challenges related to effects of NGOs on social layers, we can reach to a standard factor. To establish an organic and structural relation with NGOs, it should be ordered and structured at the local, state, and country levels and formed the working groups. As you know, the concept of partnership in all areas outlined in the constitution and it has been trying to pave the way to have pure and vibrant society and reach to the aims of establishing NGOs on the basis of historical, cultural, and religious democracy based on ethics as well as compliance with others, dignity of human rights, and gaining social security.

The starting point of modern urban management can be seen in the changes of the 1980s and 1990s. After a period of relative stagnation, about 80 themes or new concepts have emerged regarding the roles and responsibilities of governments (Falamaki, 2013). The welfare state of 1970s which had shown its ineffectiveness in the face of technical and social events replaced by minimal state and enabled the local governments under the influence of the new public management movement. The process of decentralization accelerated conversion of urban management to become a strong activity with legal authorities. Finally, positive thinking versus critical thinking, structuralist analysis in social and cultural fields, and the failure of similar solutions in different areas those were modeled from Western economic projects and focused on solving local problems to reach millennium development goals in reality and strengthen urban management especially in developing countries.

One of decentralized local institutions is municipality. Municipality organization is inside the city limits to meet the local aspects of people's developmental and welfare needs. Review of the history of establishment and development of the municipalities can be divided into four main steps. The first phase is started from Constitutional Revolution in 1309 while the second phase began from 1309 to 1328 . The third phase started from 1328 to 1334 and finally the fourth phase began 1334 onwards.

Furthermore, municipalities provide various services or goods in urban areas which all citizens can use them. So, municipal services are not limited to the certain places such as public parks and museums, police stations, fire, highways, and waste collection (Imani Jajarmi, Bigdeli, Hanachi, 2002). However due to wide range of public services and deficiency of municipal funds, the municipality provide services for the citizens through prioritizing their needs. Urban management has different objectives such as improving working and living conditions of all the population with paying attention to low-income groups and individuals, promoting sustainable economic and social development, and protecting the physical environment of the city.

Current duties of urban management regardless of the diversity and differences in social and political systems are not limited to issues such as planning, providing services, managing local culture, and carrying out development projects but they include directing and planning 
of urban activities in order to achieve sustainable development as the most important duties. A city manager should be aware of strengths and weaknesses of his city due to competitiveness of new world and try to strengthen its competitive advantages. Large cities can be defined as large organizations. In this organization, a set of institutions and practices interact to achieve their goals. Today, participation and engagement are central concepts of urban management. Urban management tries to establish and compete among public, private, and civil institutions. Also, it provides balance and coordination among three political, economic, and social aspects to facilitate the emergence of integrated cities.

\section{Concluding Remarks}

It can be argued that good governance can have 8 major characteristics: participatory, being consensus oriented, accountability, transparency, accepting responsibilities, efficiency and effectiveness, inclusiveness and non-discriminative approach towards citizens, and ultimately the rule of law. Good governance minimizes the corruption and respects minorities and vulnerable populations' opinions in its decision making. Furthermore, good governance is responsible for society's current and future needs. Good governance can be defined as the core of activities that take action to increase public interests. United Nations Development Program has mentioned some characteristics for good governance including citizen participation in policy development processes that pave the way to respect the rule of law, fair administration, and transparency which underlie the free flow of information and accountability in which the government, private sector, and other public and private institutions are accountable to the people.

Based on the discussion, assignment management and maintenance of Gonbad Sabz monument by NGOs can have many benefits for municipalities to reduce social tensions and administrative bureaucracy in municipalities and cultural heritage organization. In case of conflict in decision making, NGOs can perform as consultant. Furthermore, the main winner is the cultural heritage organization that can easily maintain cultural and historic heritage. According to the Article 44 of the constitution and the words of Iran's supreme leader about direct participation of people, experts, and elites leaving the affairs to people can be considered a test for NGOs to diligently and professionally preserve the monuments.

Finally, all efforts of this research was to contribute and support the maintenance of cultural heritage due to low municipal funds and allocate it to NGOs to prioritize the missions. Also, the factors such as globalization, privatization, changing attitudes in the government, increasing demands of citizen and civil society participation, governments' inability especially local governments in terms of financial resources and institutional capacity, increasing the problems of underdevelopment and global recommendations all suggest taking advantage of NGOs as one simple and straight approach to solve the problems and meet the challenges of tomorrow's society.

\section{References}

Cambridge University. (2001). History of Iran: Safavid era (Y. Azhand, Trans). Tehran: Jami Press.

Azhand, Y. (2000). Innovation and modernization in Safavid Art. Fine Arts, 7, 4-10.

Falamaki, M. M. (1995). Regenerating of historical buildings and cities. Tehran: University of Tehran Press. 
Falamaki, M. M. (2005). Revitalization of historical monuments and sites. Tehran: University of Tehran Press.

Falamaki, M. M. (2009a). Urban improvement and renewal ( $2^{\text {nd }}$ ed.). Samt: Teheran.

Falamaki, M. M. (2009b). Historical urban and structural recapitalization. Tehran: Tehran University Publication.

Falamaki, M. M. (2013). Modernization and urban improvement. Tehran: Faza Publications.

Hillenbrand, R. (2004). Islamic architecture: Form, function, and meaning. New York: Columbia University Press.

Hojjat, M. (1995). Cultural heritage in Iran: Policies for an Islamic Country (Unpublished doctoral dissertation). University of York, Heslington.

Imani Jajarmi, H., Bigdeli, M. \& Hanachi, S. (2002). Sustainable urban management. Tehran: The Organization for National Municipalities.

Pirnia, M. (2008). The Iranian Islamic architecture (4 ${ }^{\text {th }}$ ed.). Tehran: Sorushe Danesh. 